\title{
Guest-Adaptable and Water-Stable Peptide-Based Porous Materials by Imidazolate Side Chain Control**
}

\author{
Alexandros P. Katsoulidis, Kyo Sung Park, Dmytro Antypov, Carlos Martí-Gastaldo, \\ Gary J. Miller, John E. Warren, Craig M. Robertson, Frédéric Blanc, George R. Darling, \\ Neil G. Berry, John A. Purton, Dave J. Adams, and Matthew J. Rosseinsky*
}

\begin{abstract}
The peptide-based porous $3 D$ framework, ZnCar, has been synthesized from $\mathrm{Zn}^{2+}$ and the natural dipeptide carnosine ( $\beta$-alanyl-L-histidine). Unlike previous extended peptide networks, the imidazole side chain of the histidine residue is deprotonated to afford $\mathrm{Zn}$-imidazolate chains, with bonding similar to the zeolitic imidazolate framework (ZIF) family of porous materials. ZnCar exhibits permanent microporosity with a surface area of $448 \mathrm{~m}^{2} \mathrm{~g}^{-1}$, and its pores are $1 D$ channels with $5 \AA$ openings and a characteristic chiral shape. This compound is chemically stable in organic solvents and water. Single-crystal $X$-ray diffraction (XRD) showed that the $\mathrm{ZnCar}$ framework adapts to $\mathrm{MeOH}$ and $\mathrm{H}_{2} \mathrm{O}$ guests because of the torsional flexibility of the main His- $\beta$-Ala chain, while retaining the rigidity conferred by the $\mathrm{Zn}$-imidazolate chains. The conformation adopted by carnosine is driven by the $H$ bonds formed both to other dipeptides and to the guests, permitting the observed structural transformations.
\end{abstract}

$M$ etal-organic frameworks (MOFs) are crystalline porous materials composed of inorganic nodes, either single ions or clusters of ions, bridged by organic linkers through metalligand coordination bonds. ${ }^{[1]}$ Recently, several biomolecules, such as amino acids, ${ }^{[2]}$ nucleobases, ${ }^{[3]}$ saccharides, ${ }^{[4]}$ and peptides, ${ }^{[5]}$ were used as organic linkers in MOF synthesis, mainly because of the diversity of their metal binding sites. The incorporation of biomolecules in MOFs also attracts particular attention because they can improve the biocom-

[*] Dr. A. P. Katsoulidis, Dr. K. S. Park, Dr. D. Antypov,

Dr. C. Martí-Gastaldo, Dr. G. J. Miller, Dr. J. E. Warren,

Dr. C. M. Robertson, Dr. F. Blanc, Dr. G. R. Darling, Dr. N. G. Berry,

Dr. D. J. Adams, Prof. M. J. Rosseinsky

Department of Chemistry, University of Liverpool

Crown Street, Liverpool, L69 7ZD (UK)

E-mail: m.j.rosseinsky@liverpool.ac.uk

Dr. J. A. Purton

Daresbury Laboratory, Science \& Technologies Facilities Council Kerkwick Lane, Warrington, WA4 4AD (UK)

[**: Financial support from the EPSRC under EP/J008834 and EP/ H000925 is gratefully acknowledged. We would like to acknowledge the "Materials Chemistry Consortium" (the EPSRC grant EP/ L000202) for providing computational resources for this project. Supporting information for this article is available on the WWW under http://dx.doi.org/10.1002/anie.201307074.

o (C) 2014 The Authors. Published by Wiley-VCH Verlag GmbH \& Co. $\mathrm{KGaA}$. This is an open access article under the terms of the Creative Commons Attribution License, which permits use, distribution and reproduction in any medium, provided the original work is properly cited. patibility of the final products, enhance the structural and chemical diversity of the internal surfaces of MOFs, and afford chiral frameworks that may have unique separation and catalytic properties. ${ }^{[6]}$

Peptides are particularly interesting as linkers because dipeptides with hydrophobic residues that are held together by $\mathrm{H}$ bonds form metal-free purely peptide-based porous materials. These structures are divided into two groups, the Val-Ala compounds with hydrophobic pores and the Phe-Phe compounds with hydrophilic pores. ${ }^{[7]}$ The Val-Ala structures exhibit typical $\mathrm{CO}_{2}$ and $\mathrm{CH}_{4}$ adsorption for microporous materials. ${ }^{[8]}$

In MOFs, peptides have the ability to act as connecting ligands as they have at least one amino and one carboxylic acid terminus that can coordinate metal ions. The dipeptides Gly-Ala and Gly-Thr thus connect $\mathrm{Zn}^{2+}$ ions to form two topologically distinct 2D-layered framework compounds, $\mathrm{Zn}$ (Gly-Ala $)_{2}$ and $\mathrm{Zn}(\mathrm{Gly}-\mathrm{Thr})_{2}$, respectively. ${ }^{[9]}$ The former is a flexible porous material that displays an adaptable pore conformation, which evolves continuously from an open to a partially disordered closed structure in response to the level of guest loading. The latter is structurally rigid to guest loss in a manner characteristic of rigid MOFs and exhibits permanent porosity with a surface area of $200 \mathrm{~m}^{2} \mathrm{~g}^{-1}$ after solvent removal, as the framework is stabilized by the additional $\mathrm{H}$ bonding between the $\mathrm{OH}$ functional group from the threonine side chain and the $\mathrm{NH}_{2}$ terminal group. These two examples clearly show how diverse the structures can be and the strong control of adsorption behavior arising from small changes in the peptide unit.

Here we present a new peptide-based MOF, ZnCar-DMF, which is assembled from $\mathrm{Zn}^{2+}$ and carnosine (Car), a natural dipeptide with the molecular structure $\beta$-alanyl-L-histidine. The peptidic chain of carnosine contains an extra $\mathrm{CH}_{2}$ group compared to classic dipeptides, because of the $\beta$-amino acid structure of $\beta$-alanine. The histidine residue incorporates the imidazole moiety that serves as an additional metal binding site, and thus carnosine has two more potential linking points compared to Gly-Ala and Gly-Thr. In reported histidinecontaining framework compounds the imidazole ring is neutral and binds only one metal atom at N3. ${ }^{[10]} \mathrm{ZnCar} \cdot \mathrm{DMF}$ is a 3D framework compound in which each carnosine molecule links four tetrahedral $\mathrm{Zn}$ cations, two of which are bridged by the deprotonated imidazolate ring. The structure is flexible and displays 1D permanent porosity upon removal of DMF. It is a microporous material with a specific surface area of $448 \mathrm{~m}^{2} \mathrm{~g}^{-1}$ and exhibits strong binding affinity for small molecules, such as $\mathrm{CO}_{2}$ and $\mathrm{CH}_{4}$. This MOF is not dissolved or 
decomposed in either $\mathrm{H}_{2} \mathrm{O}$ or $\mathrm{MeOH}$. Moreover, after resolvation in $\mathrm{MeOH}$ and $\mathrm{H}_{2} \mathrm{O}$, it adopts structures different from that of the as-made or desolvated material. Singlecrystal X-ray diffraction studies showed that this flexibility is driven by $\mathrm{H}$ bonds formed between the guests and the dipeptide, leading to different torsional conformations of carnosine.

Crystals of $\mathrm{ZnCar} \cdot \mathrm{DMF}$ in the shape of rectangular prisms and 50 to $100 \mu \mathrm{m}$ in length (Supporting Information, Figure S1) were obtained from the reaction of zinc nitrate with carnosine in $\mathrm{DMF} / \mathrm{H}_{2} \mathrm{O}$ at $100^{\circ} \mathrm{C}$ for 12 hours (see the Experimental Section in the Supporting Information). Under these conditions, both the imidazole N1 and the carboxy group of the carnosine are deprotonated to form the $\mathrm{Car}^{2-}$ anion, allowing the formation of a $4: 4$ motif with $\mathrm{Zn}^{2+}$ (Scheme 1). The $\mathrm{Zn}$ cations are tetrahedrally coordinated to

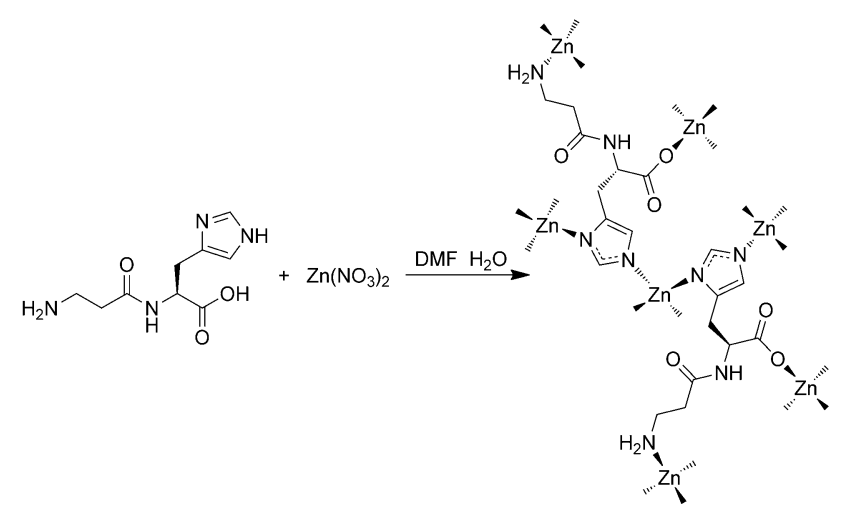

Scheme 1. Formation of $\mathrm{ZnCar}$. DMF from the reaction between $\mathrm{Zn}\left(\mathrm{NO}_{3}\right)_{2}$ and carnosine.

four carnosine ligands (Scheme 1), and each ligand is coordinated to four $\mathrm{Zn}^{2+}$ ions by the C-terminal His carboxylate group, the $\mathrm{N}$-terminal Ala amine group, and the two nitrogen atoms of the imidazole ring (Scheme 1). The chemistry and the bridging connectivity between the side chain imidazole of histidine and the $\mathrm{Zn}$ cations are reminiscent of those seen in ZIF compounds. ${ }^{[11]}$ The molecular cyclic tetramer $\left[\mathrm{Au}\left(\mathrm{gly}-\mathrm{L}-\mathrm{his}^{3-}\right)\right]_{4} \cdot 10 \mathrm{H}_{2} \mathrm{O}$ is the only other known compound of histidine where metal-imidazolate bonding is employed. ${ }^{[12]}$

ZnCar.DMF crystallizes in the chiral monoclinic space group $\mathrm{P} 2_{1}$ and its $3 \mathrm{D}$ structure is directed by the carnosine conformation (Figure $1 \mathrm{a}$ ), as the $\mathrm{Zn}$ cations connected to the histidine moiety define a plane and the residue of the $\mathrm{N}$ terminal $\beta$-alanine is extended to the third dimension. The imidazolate rings (im) and $\mathrm{Zn}$ cations form a zigzag chain where the rings adopt a trans conformation (Figure $1 \mathrm{~b}$ ) and the $\mathrm{Zn}$-im- $\mathrm{Zn}$ angle is $138^{\circ}$ (Figure S2), which is smaller than the $145^{\circ}$ angle found in ZIFs. ${ }^{[11 a]}$ This chain is similar to the linear structures of univalent metal-imidazolate compounds. ${ }^{[13]}$ The chains are linked through the histidine carboxylate group (Figure 1b) to form undulating layers (parallel to the 100 plane) that are interconnected by the antiparallel-oriented $\beta$-alanine residues (Figure 1c). The framework is further stabilized by two $\mathrm{H}$ bonds, an intramolecular bond between the carboxy oxygen atom and amino hydrogen atom of $\beta$-alanine, and an intermolecular bond between the carboxylate oxygen atom of histidine and the neighboring amide hydrogen atom (Figure $1 \mathrm{a}$ and $\mathrm{c}$ ). The arrangement of carnosine forms 1D square-shaped pores, filled with DMF and running parallel to the crystallographic $b$ axis (Figure $1 \mathrm{~d}$ ). The chiral shape of the pore walls is depicted using the Connolly surface representation (Figure $1 \mathrm{e}$ ). The pores can be viewed as relatively large cavities, with diameters of $d_{1}=5.18 \AA$, connected in a zig-zag fashion by narrow channels with diameters of $d_{2}=3.78 \AA$.

The structure and the composition of $\mathrm{ZnCar} \cdot \mathrm{DMF}$, obtained from single-crystal $\mathrm{X}$-ray diffraction data are in good agreement with the characterization results of the bulk sample. The powder XRD pattern perfectly matches the simulated pattern from the single-crystal structure and is indexed to the same unit cell (Figure S3 and Table S1). CHN analysis results are very close to theoretical values (Table S2) and the DMF content, calculated as $20 \mathrm{wt} \%$ from the singlecrystal data, was verified by thermogravimetric analysis (TGA; Figure S4). The solid-state ${ }^{13} \mathrm{C}$ CPMAS NMR spectrum of $\mathrm{ZnCar} \cdot \mathrm{DMF}$ displays all the expected resonances for carnosine and three resonances for DMF (Figure S5) at room temperature.

The ZnCar.DMF framework is structurally flexible and displays permanent porosity after the removal of DMF, as demonstrated by the variable-temperature single-crystal $\mathrm{X}$ ray diffraction data. While the crystallinity of the material is retained over the whole temperature range that was studied, the unit-cell volume decreases sharply from 762.82 to $726.78 \AA^{3}$ (by $\approx 5 \%$ ) between 388 and $394 \mathrm{~K}$ as DMF is removed from the pores (Figure S6). The relaxation of the ZnCar framework from the DMF-solvated state at $388 \mathrm{~K}$ (Figure 2a) to the desolvated state at $394 \mathrm{~K}$ (Figure 2 b) results in an alternate linker conformation. The torsion angles of the peptidic chain change by $20-30^{\circ}$ (Figure S7) with the exception of the rigid $\omega$ angle C7-N8-C9-C14, which corresponds to the peptide bond itself. The structure of the pore was also altered, having cavities with diameters of $d_{1}=4.58 \AA$ connected by channels with diameters of $d_{2}=4.18 \AA$ (Table S3). In contrast, the three torsional angles responsible for the orientation of the imidazolate ring and the carboxylate group on histidine each changed by less than $2^{\circ}$, indicating the rigidity of the $b c$ planes shown in Figure $1 b$.

The bulk desolvation of ZnCar-DMF was achieved by evacuation on a high-vacuum line $\left(10^{-5} \mathrm{mbar}\right)$ at $130^{\circ} \mathrm{C}$ for 5 hours. The structure of the evacuated sample, $\mathrm{ZnCar}$, was confirmed by powder XRD and the complete removal of DMF was verified by TGA (Figure S8). The porous properties of desolvated $\mathrm{ZnCar}$ were investigated with the $\mathrm{CO}_{2}$ adsorption-desorption isotherm (Figure S9) obtained at $195 \mathrm{~K}$ up to 1 bar. ZnCar is purely microporous, as the isotherm shape corresponds to that of type I according to the IUPAC classification. The BET surface area is calculated as $448 \mathrm{~m}^{2} \mathrm{~g}^{-1}$ using the relative pressure range, $0.01<P / P_{\mathrm{o}}<0.1$. The total pore volume, estimated at $0.19 \mathrm{~cm}^{3} \mathrm{~g}^{-1}$, is slightly smaller than the solvent-accessible volume of the desolvated $\mathrm{ZnCar}$ structure of $0.21 \mathrm{~cm}^{3} \mathrm{~g}^{-1}$. The isotherm shows no gate 
a)

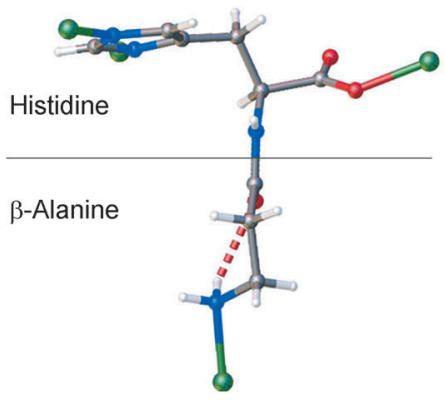

b)
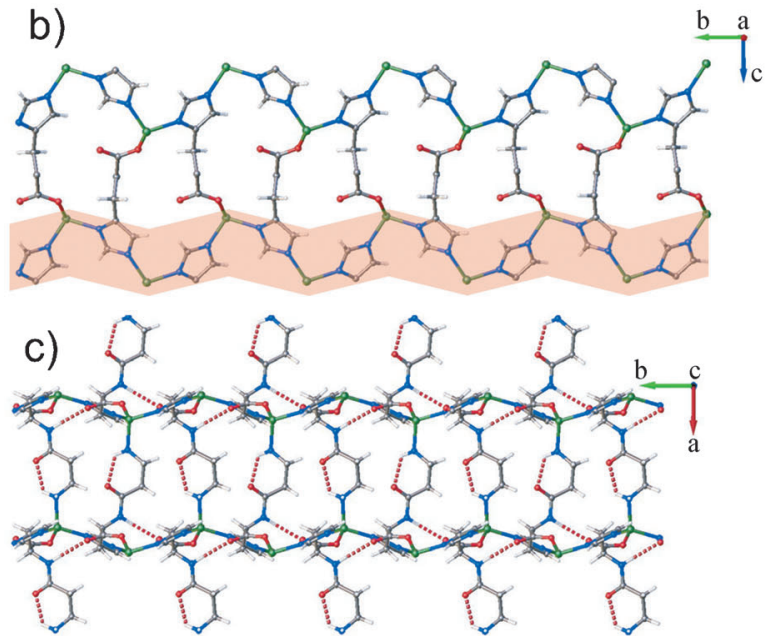

d)

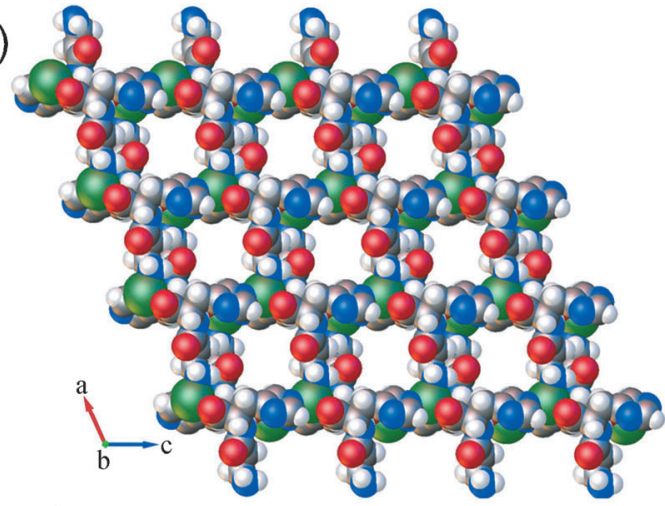

e)

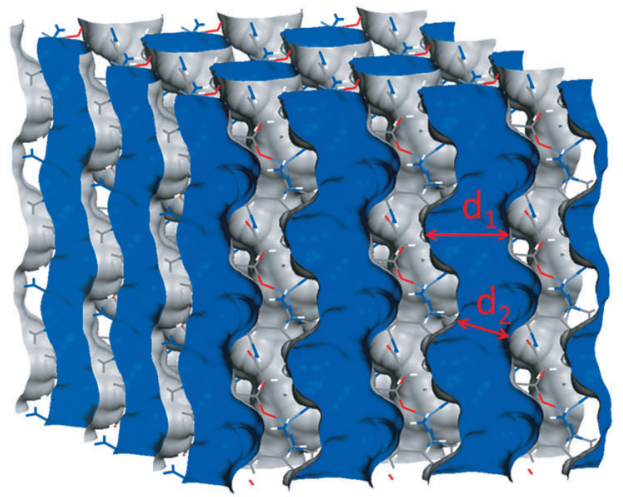

Figure 1. a) $3 \mathrm{D}$ conformation of carnosine connected to four $\mathrm{Zn}$ cations. The dashed line corresponds to the intramolecular $\mathrm{H}$ bond between a carboxy oxygen atom and an amino hydrogen atom. Three Zn cations are bound to histidine (above the line) and the fourth to $\beta$-alanine (below the line). b) Zn cations and imidazolate rings form the zig-zag chain (highlighted) that is the rigid part of the structure. The chains are linked through the histidine carboxylate group. c) Undulating layers of imidazolate rings interconnected by antiparallel-oriented $\beta$-alanine residues. Intermolecular $\mathrm{H}$ bonds are formed between the carboxylate oxygen atom and the amide hydrogen atom. d) Space-filling representation of ZnCar viewed along the b axis, showing the 1D pores. e) Connolly surface representation of the pore walls, calculated with a probe radius of $1.4 \AA$. The pores consist of cavities with diameters of $d_{1}=5.18 \AA$ and narrow channels with diameters of $d_{2}=3.78 \AA$.

opening, but a low pressure hysteresis loop associated with the strong adsorption of $\mathrm{CO}_{2}$.

The chemical stability of ZnCar·DMF was examined by soaking fresh material in water under stirring for 3 days (Table S4). ICP analysis of the supernatant aqueous solution every 24 hours showed very low $\mathrm{Zn}$ leaching, corresponding to $1.7 \mathrm{wt} \%$ of the $\mathrm{Zn}$ added to water in the form of ZnCar.DMF. The stability of ZnCar.DMF in water, unlike $\mathrm{Zn}(\mathrm{Gly}-\mathrm{Ala})_{2}$ and $\mathrm{Zn}(\mathrm{Gly}-\mathrm{Thr})_{2}$ frameworks, which are stable only in organic solvents, is attributed to the $\mathrm{Zn}$ imidazolate bonding that is the basis of the chemical stability of ZIFs.

To study the stability and the interaction of this framework with different guest molecules, desolvated crystals of $\mathrm{ZnCar}$ were immersed in $\mathrm{H}_{2} \mathrm{O}$ and $\mathrm{MeOH}$. The resolvated crystals resulted in two new structures, $\mathrm{ZnCar} \cdot \mathrm{MeOH}$ and $\mathrm{ZnCar} \cdot \mathrm{H}_{2} \mathrm{O}$. The $\mathrm{ZnCar}$ framework proved to be adaptable to the presence of guest molecules, as the peptide conformation changed in both cases without breaking the 4:4 connectivity motif between $\mathrm{Zn}$ and carnosine. $\mathrm{ZnCar} \cdot \mathrm{MeOH}$ adopts the monoclinic $P 2_{1}$ space group with slightly altered unit-cell parameters, but without significant changes in the pore shape compared to the desolvated structure (Figure $2 \mathrm{c}$ ). The torsion angles of carnosine in $\mathrm{ZnCar} \cdot \mathrm{MeOH}$ are in a range between those in the structure containing DMF and the desolvated structure (Figure S7). Using MD simulations, we found that the carboxy oxygen atom of alanine in the desolvated structure is sterically screened from forming an $\mathrm{H}$ bond with a methanol molecule (Figure S10). Hence, the main structural change caused by the addition of $\mathrm{MeOH}$ is the rotation of the carboxy oxygen atom toward the pore where it can now form an $\mathrm{H}$ bond with a guest molecule (each $\mathrm{MeOH}$ molecule also works as an acceptor and forms an additional $\mathrm{H}$ bond with the amine group) (Figure S11b). In the as-made material, the same carboxy oxygen atom forms an intramolecular $\mathrm{H}$ bond with one of the two hydrogen atoms on the amine group, while the DMF molecule is bound to the other hydrogen atom (Figure S11a). The DFT-calculated steepest descent energy minimization of solvent-free $\mathrm{ZnCar} \cdot \mathrm{DMF}$ and $\mathrm{ZnCar} \cdot \mathrm{MeOH}$ unit cells showed that both systems relax to assume the structure of the empty framework. This means that both DMF and $\mathrm{MeOH}$ guests distort the framework locally by $\mathrm{H}$ bonding without inducing a phase transition in the framework itself (Figure S12). $\mathrm{MeOH}$ vapor adsorption on $\mathrm{ZnCar}$, collected at 


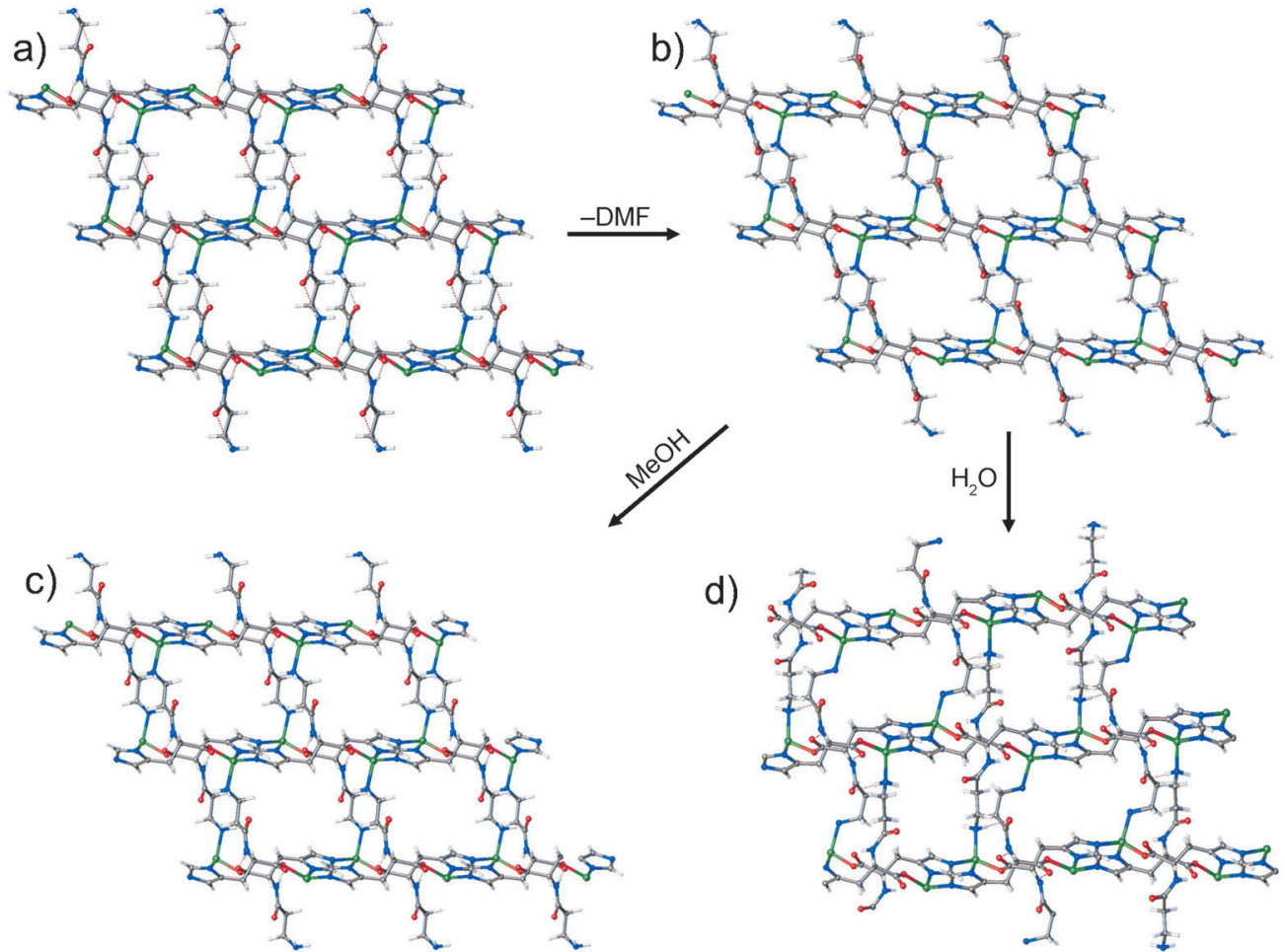

Figure 2. The structures of a) $\mathrm{ZnCar} \cdot \mathrm{DMF}$, b) desolvated $\mathrm{ZnCar}, \mathrm{c}$ ) resolvated $\mathrm{ZnCar} \cdot \mathrm{MeOH}$, and d) resolvated $\mathrm{ZnCar} \cdot \mathrm{H}_{2} \mathrm{O}$. ZnCar.DMF, $\mathrm{ZnCar}$, and $\mathrm{ZnCar} \cdot \mathrm{MeOH}$ show one type of pore with square or parallelogram shape. $\mathrm{ZnCar} \cdot \mathrm{H}_{2} \mathrm{O}$ has two types of pores.

three different temperatures, reaches a maximum of $16 \mathrm{wt} \%$ (Figure S13). Desolvation of $\mathrm{ZnCar} \cdot \mathrm{MeOH}$ again produces the $\mathrm{ZnCar}$ structure (Figure S14), which is as porous as the original DMF-desolvated ZnCar material (Figure S15), thus demonstrating the repeatability of loading and unloading $\mathrm{MeOH}$ from $\mathrm{ZnCar}$.

The structure of the water-resolvated $\mathrm{ZnCar} \cdot \mathrm{H}_{2} \mathrm{O}$ is different, as carnosine adopts two distinct conformations, carnosine 1 and carnosine 2 (Figure S7), which form different sets of $\mathrm{H}$ bonds. Thus, two types of pores are formed, a wide and a narrow one (Figure $2 \mathrm{~d}$ ), and the volume of the unit cell is doubled compared to those of the other three structures. The positions of the water oxygen atoms in both the narrow and the wide pores were determined from the single-crystal diffraction data with the hydrogen atoms added at calculated positions. The orientations of the water molecules were then refined using DFT calculations (Table S6). The carnosine 2 molecule defines a wide pore space, filled by eight $\mathrm{H}_{2} \mathrm{O}$ molecules per unit cell, and exhibits a conformation similar to those of the $\mathrm{MeOH}$-containing structure, but with the amine group pointing in the opposite direction. Carnosine 2 forms six $\mathrm{H}$ bonds (Figure $3 \mathrm{a}$ ), three within the framework and three with $\mathrm{H}_{2} \mathrm{O}$. The narrow pore is filled with four $\mathrm{H}_{2} \mathrm{O}$ molecules and is bound by carnosine 1 , in which the torsion angles of the peptidic chain (Figure S7) were significantly changed compared to those of all the other structures (Figure $2 \mathrm{a}-\mathrm{c}$ ). Carnosine 1 forms three $\mathrm{H}$ bonds (Figure $3 \mathrm{~b}$ ), one within the framework and two with $\mathrm{H}_{2} \mathrm{O}$. The intraframework $\mathrm{H}$ bond between the carboxylate oxygen atom and amide hydrogen atom, present in the three previous struc- tures, appears only in carnosine 2 in $\mathrm{ZnCar} \cdot \mathrm{H}_{2} \mathrm{O}$. The $\mathrm{H}_{2} \mathrm{O}$ molecules are interconnected by $\mathrm{H}$ bonds forming a network inside the pores. In particular, two out of four distinct $\mathrm{H}_{2} \mathrm{O}$ molecules in the wide pore form the maximum possible four $\mathrm{H}$ bonds, two of which are with the framework (Figure S16a). In the narrow pore, there are two distinct $\mathrm{H}_{2} \mathrm{O}$ molecules that form three and two $\mathrm{H}$ bonds, respectively (Figure S16b).The desolvated $\mathrm{ZnCar}$ structure is obtained after $\mathrm{H}_{2} \mathrm{O}$ removal (Figure S17) and the experimentally measured pore volume, $0.21 \mathrm{~cm}^{3} \mathrm{~g}^{-1}$ (Figure S18), equals to the estimated value from the ZnCar single-crystal structure. $\mathrm{H}_{2} \mathrm{O}$ vapor adsorption isotherms on $\mathrm{ZnCar}$ exhibit broad hysteresis loops and a maximum uptake of $15 \mathrm{wt} \%$ (Figure S19), and were cycled three times without change. The exhibited reversible resolvation-desolvation of the $\mathrm{ZnCar}$ framework with $\mathrm{H}_{2} \mathrm{O}$ proves that the properties of $\mathrm{ZnCar}$ remain unaffected after its exposure to water. Unlike $\mathrm{ZnCar} \cdot \mathrm{MeOH}$ and $\mathrm{ZnCar} \cdot \mathrm{DMF}$, the DFT-calculated energy minimization of the empty $\mathrm{ZnCar} \cdot \mathrm{H}_{2} \mathrm{O}$ structure did not converge to that of the desolvated material, but relaxed to a different stable state that was $53 \mathrm{~kJ} \mathrm{~mol}^{-1}$ higher in energy (Table S6). This means that the desolvated $\mathrm{ZnCar}$ and $\mathrm{ZnCar} \cdot \mathrm{H}_{2} \mathrm{O}$ structures are separated by an energy barrier, and the calculated energy increase for the framework is counterbalanced experimentally by the formation of the water network that is rich in $\mathrm{H}$ bonds. The framework transformations, driven by the different guests, are facilitated mainly by the torsional flexibility of the peptidic chain. The 2D layers constructed from the $\mathrm{Zn}$-imidazolate chains constitute the rigid part of the framework, as indicated by small changes in the $\mathrm{Zn}$-im-Zn angle, the $\mathrm{Zn}-\mathrm{Zn}$ distance, and the distance between the chains (Table S7).

High pressure $\mathrm{CO}_{2}$ and $\mathrm{CH}_{4}$ adsorption isotherms of ZnCar were collected at 283, 293, and $303 \mathrm{~K}$ (Figure S20). The gravimetric uptakes were found to be around $19 \mathrm{wt} \%$ for $\mathrm{CO}_{2}$ and $5 \mathrm{wt} \%$ for $\mathrm{CH}_{4}$ at 15 bars. The isotherms are of type I, and in each case $80 \%$ of total uptake was adsorbed at 4 bars, showing the entirely microporous character of this material. The ZnCar MOF exhibits strong binding affinity for both gases, as shown by the isosteric heat of adsorption $Q_{\text {st }}$ (Figure S21). For $\mathrm{CO}_{2}$, the $Q_{\text {st }}$ value at zero coverage is $49 \mathrm{~kJ} \mathrm{~mol}^{-1}$, which is amongst the highest ever reported for MOFs. Cu-BTTri-mmen exhibits a $Q_{\text {st }}$ value of $96 \mathrm{~kJ} \mathrm{~mol}^{-1},{ }^{[14]}$ 


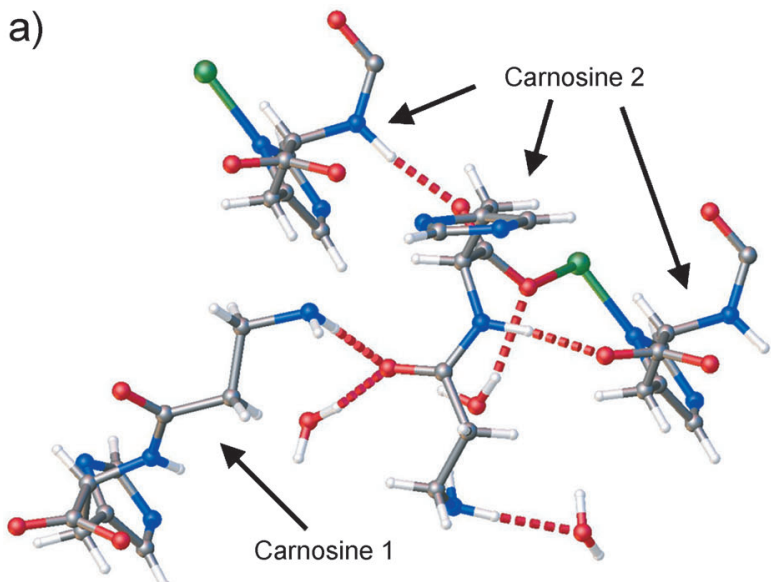

b)

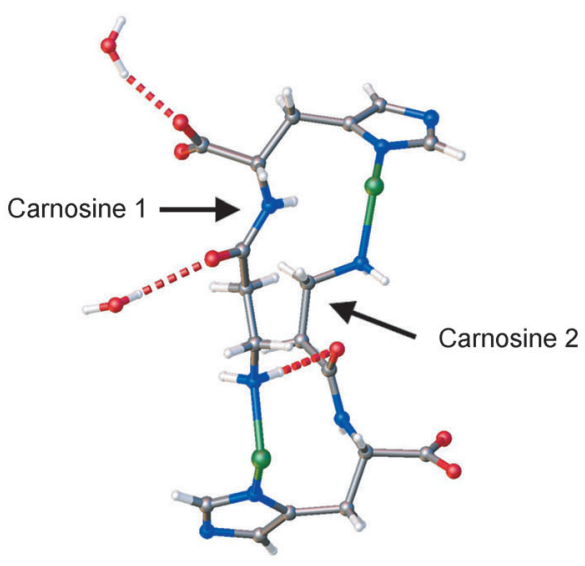

Figure 3. $\mathrm{H}$ bonds in $\mathrm{ZnCar} \cdot \mathrm{H}_{2} \mathrm{O}$. a) Carnosine 2 has six $\mathrm{H}$ bonds in total. Three of them are within the framework, one with carnosine 1 and two with carnosine 2, and the other three with $\mathrm{H}_{2} \mathrm{O}$. b) Carnosine 1 has three $\mathrm{H}$ bonds, one of which is in the framework with carnosine 2 and the other two with $\mathrm{H}_{2} \mathrm{O}$.

and for the most microporous MOF, the $Q_{\text {st }}$ at zero coverage ranges from $25-50 \mathrm{~kJ} \mathrm{~mol}^{-1}$. ${ }^{[15]}$ Our DFT calculations indicate that most of this energy can be attributed to the dispersion interactions (Table S8), in particular between the imidazole ring and the $\mathrm{CO}_{2}$ carbon atom (Figure S22). The molecular dynamics (MD) simulations of $\mathrm{CO}_{2}$ diffusion along the pores have also shown this configuration to be the most favorable for adsorption, and showed that the $\mathrm{CO}_{2}$ molecules diffuse by hopping between the cavities in the pore structure through smaller channels that connect the pores (Figure 1e and Figure S22). The $Q_{\text {st }}$ for $\mathrm{CH}_{4}$ adsorption at zero coverage is $27 \mathrm{~kJ} \mathrm{~mol}^{-1}$, which is also a high value for MOFs, ${ }^{[16]}$ very close to the highest reported $Q_{\text {st }}$ value $30 \mathrm{~kJ} \mathrm{~mol}^{-1}$ for PCN-14. ${ }^{[17]}$

The selectivity of adsorption between $\mathrm{CO}_{2}$ and $\mathrm{CH}_{4}$ was estimated using the IAST model at $303 \mathrm{~K}$ for the equimolar gas mixture, and shows a value of 10 for the whole pressure range (Figure S23). This is a moderate value for MOFs, lower than that of $\mathrm{Mg}_{2}$ (dobdc), which is $60,{ }^{[18]}$ in accordance with the high adsorption affinity of $\mathrm{ZnCar}$ for both gases.

The $\beta$-dipeptide carnosine is a special MOF linker that offers chemical stability, structural diversity and chirality, and permanent porosity in the ZnCar.DMF compound. $\mathrm{ZnCar} \cdot \mathrm{DMF}$ is an analogue of ZIFs where the involvement of the imidazole ring of the histidine side chain in $\mathrm{Zn}$ imidazolate bonding both affords the chemical stability of the framework in water and produces a 3D structure, in contrast to previously studied peptide-based MOFs. The main His- $\beta$ Ala chain connects the rigid imidazolate-based layers, retaining its flexibility and conferring structural adaptability on the framework in the presence of different guest molecules. The ZnCar framework exhibits permanent microporosity and strong adsorption affinity for $\mathrm{CO}_{2}$ and $\mathrm{CH}_{4}$.

Received: August 12, 2013

Revised: October 23, 2013

Published online: December 2, 2013

Keywords: imidazolates - metal-organic frameworks . microporous materials - peptides · structural adaptability

[1] See the special issues: a) Chem. Soc. Rev. 2009, 38, 1201-1508; b) H.-C. Zhou, J. R. Long, O. M. Yaghi, Chem. Rev. 2012, 112, $673-1268$.

[2] a) E. V. Anokhina, A. J. Jacobson, J. Am. Chem. Soc. 2004, 126, 3044-3045; b) E. V. Anokhina, Y. B. Go, Y. Lee, T. Vogt, A. J. Jacobson, J. Am. Chem. Soc. 2006, 128, 9957-9962; c) J. Perez Barrio, J.-N. Rebilly, B. Carter, D. Bradshaw, J. Bacsa, A. Y. Ganin, H. Park, A. Trewin, R. Vaidhyanathan, A. I. Cooper, J. E. Warren, M. J. Rosseinsky, Chem. Eur. J. 2008, 14, 4521-4532; d) R. Vaidhyanathan, D. Bradshaw, J.-N. Rebilly, J. P. Barrio, J. A. Gould, N. G. Berry, M. J. Rosseinsky, Angew. Chem. 2006, 118, 6645-6649; Angew. Chem. Int. Ed. 2006, 45, 6495-6499; e) P. Zhu, W. Gu, F.-Y. Cheng, X. Liu, J. Chen, S.-P. Yan, D.-Z. Liao, CrystEngComm 2008, 10, $963-967$.

[3] a) K. C. Stylianou, J. E. Warren, S. Y. Chong, J. Rabone, J. Bacsa, D. Bradshaw, M. J. Rosseinsky, Chem. Commun. 2011, 47, 33893391; b) J. An, S. J. Geib, N. L. Rosi, J. Am. Chem. Soc. 2009, 131, 8376-8377; c) J. An, O. K. Farha, J. T. Hupp, E. Pohl, J. I. Yeh, N. L. Rosi, Nat. Commun. 2012, 3, 604.

[4] R. A. Smaldone, R. S. Forgan, H. Furukawa, J. J. Gassensmith, A. M. Z. Slawin, O. M. Yaghi, J. F. Stoddart, Angew. Chem. 2010, 122, 8812-8816; Angew. Chem. Int. Ed. 2010, 49, 8630-8634.

[5] a) T. Takayama, S. Ohuchida, Y. Koike, M. Watanabe, D. Hashizume, Y. Ohashi, Bull. Chem. Soc. Jpn. 1996, 69, 15791586; b) E. Ueda, Y. Yoshikawa, N. Kishimoto, M. Tadokoro, H. Sakurai, N. Kajiwara, Y. Kojima, Bull. Chem. Soc. Jpn. 2004, 77, 981 -986; c) A. Mantion, L. Massüger, P. Rabu, C. Palivan, L. B. McCusker, A. Taubert, J. Am. Chem. Soc. 2008, 130, 2517-2526.

[6] I. Imaz, M. Rubio-Martinez, J. An, I. Sole-Font, N. L. Rosi, D. Maspoch, Chem. Commun. 2011, 47, 7287-7302.

[7] C. H. Görbitz, Chem. Eur. J. 2007, 13, 1022-1031.

[8] A. Comotti, S. Bracco, G. Distefano, P. Sozzani, Chem. Commun. 2009, 284-286.

[9] a) J. Rabone, Y. F. Yue, S. Y. Chong, K. C. Stylianou, J. Bacsa, D. Bradshaw, G. R. Darling, N. G. Berry, Y. Z. Khimyak, A. Y. Ganin, P. Wiper, J. B. Claridge, M. J. Rosseinsky, Science 2010, 329, 1053-1057; b) C. Martí-Gastaldo, J. E. Warren, K. C. Stylianou, N. L. O. Flack, M. J. Rosseinsky, Angew. Chem. 2012, 124, 11206-11210; Angew. Chem. Int. Ed. 2012, 51, $11044-11048$

[10] a) L. Chen, X. Bu, Chem. Mater. 2006, 18, 1857-1860; b) J. Fan, C. Slebodnick, R. Angel, B. E. Hanson, Inorg. Chem. 2005, 44, $552-558$.

[11] a) K. S. Park, Z. Ni, A. P. Côté, J. Y. Choi, R. Huang, F. J. UribeRomo, H. K. Chae, M. O'Keeffe, O. M. Yaghi, Proc. Natl. Acad. 


\section{Angewandte}

Sci. USA 2006, 103, 10186-10191; b) R. Banerjee, A. Phan, B. Wang, C. Knobler, H. Furukawa, M. O'Keeffe, O. M. Yaghi, Science 2008, 319, 939-943.

[12] M. Wienken, B. Lippert, E. Zangrando, L. Randaccio, Inorg. Chem. 1992, 31, 1983-1985.

[13] a) X.-C. Huang, J.-P. Zhang, X.-M. Chen, Cryst. Growth Des. 2006, 6, 1194-1198; b) J.-P. Zhang, Y.-B. Zhang, J.-B. Lin, X.-M Chen, Chem. Rev. 2011, 111, 1001-1033.

[14] T. M. McDonald, D. M. D'Alessandro, R. Krishna, J. R. Long, Chem. Sci. 2011, 2, 2022-2028.
[15] K. Sumida, D. L. Rogow, J. A. Mason, T. M. McDonald, E. D. Bloch, Z. R. Herm, T.-H. Bae, J. R. Long, Chem. Rev. 2011, 111, $724-781$.

[16] K. Konstas, T. Osl, Y. Yang, M. Batten, N. Burke, A. J. Hill, M. R. Hill, J. Mater. Chem. 2012, 22, $16698-16708$.

[17] S. Ma, D. Sun, J. M. Simmons, C. D. Collier, D. Yuan, H.-C. Zhou, J. Am. Chem. Soc. 2007, 129, 1012-1016.

[18] Z. R. Herm, R. Krishna, J. R. Long, Microporous Mesoporous Mater. 2012, 151, $481-487$. 